\title{
SOME NEW GENERA AND SPECIES OF ATTIDAE FROM SOUTH AFRICA.
}

BY GEORGE W. PECKHAM AND ELIZABETH G. PECKHAM, MILWAUKEe, WIS.

\section{FISSIDENTATI.}

Tusitala, gen. nov.

The cephalothorax is high, with the sides sloping outward from the upper surface and widening in a gentle curve from front to back, the widest point being behind the dorsal eyes. The cephalic part is inclined forward, and the thoracic rounds off rather steeply from the third row of eyes. The quadrangle occupies from two-fifths to nearly one-half of the cephalothorax, is one-third wider than long and is wider behind than in front. The first row of eyes is straight or a little curved down, the eyes are large, the middle being less than twice the size of the lateral and subtouching, while the lateral are well separated from them. The second row is equally distant from the first and third or is a little nearer the first, and the third is narrower than the cephalothorax. The falces are long, strong, and vertical, and are bowed, with a compound tooth on the inferior margin. The males have a stiff ridge of hairs on the front face. The sternum is oblong and truncated. The first coxae are separated by about the width of the labium, which $\mathrm{i}$ longer than wide.

This genus is founded upon T. barbata and includes a second species, $T$. hirsuta, both from South Africa.
Tusitala barbata, sp. nov.

§. Length $6.5 \mathrm{~mm}$. Legs 1432 , about equal in thickness. The first pair is plainly the longest but the others do not differ much in length.

The cephalothorax is covered with a mixture of red, yellow and white hairs, the red predominating on the sides, and the white on the upper surface. The clypeus is less than half as wide as the middle eyes of the first row, and is yellow with a few white hairs. The falces are light brown, and have a remarkable ornament in the shape of a long ridge of stiff hairs down the front face. These hairs stand out stiflly, but their tips curve inward to meet those of the opposite side in the middle line. Their color is snowywhite on the upper half and deep black on the lower. The palpus is slender with long joints, the tibia much exceeding the tarsus. The femur and tarsus are dark colored, the patella and tibia, pale. The legs are brown with darker bars. The abdomen is covered with a mixture of gray and brown hairs. There is a white band around the base, and the posterior dorsum has some indistinct white chevrons.

We have six males from Algoa Bay, South Africa, sent to us by Dr. Braun.

\section{Tusitala hirsuta, sp. nov.}

§. Length $8 \mathrm{~mm}$. Legs $\overline{1234}$, first and second a little the stoutest.

In our single specimen the cephalothorax is much darker than the abdomen, but both are rubbed quite bare of markings excepting some long white hairs at the front end of the abdomen. The clypeus is as wide as the large 
eyes of the first row, and is brown with long white hairs. The falces are long and strongly bowed, approaching each other at the extremities. They have ridges of stiff hairs, as in $T$. barbata, on the front faces, which are light brown in color and grow longer and thicker in the lower than in the upper half. The palpus is long and slender, the tibia being much longer than the tarsus. The patella and tibia are much lighter in color than the femur and tarsus. The legs are brown, the first and second pairs being darker than the third and fourth.

We have one male from Zululand, given to us by Rev. Henry C. McCook.

\section{Monclova, gen. nov.}

The cephalothorax is long, with nearly parallel sides, which narrow a little at the posterior end. It is moderately high at the third row of eyes, from which point it slopes abruptly in both directions, but more steeply behind than in front. The quadrangle of the eyes occupies nearly half of the cephalothorax, is a little wider behind than in front, and is one-third wider than long. The first row is very slightly curved downward, with the middle eyes subtouching and less than twice as large as the lateral, which are a little separated from them. The second row is about halfway between the first and the third. The third row is as wide as the cephalothorax. The falces are vertical and parallel. The sternum is oval, truncated in front, and narrows in front and behind. The first coxae are separated by the width of the labium, which is about as wide as long.
The type is a new species from South Africa, $M$. braunii.

\section{Monclova braunit, sp. nov.}

9. Length $7 \mathrm{~mm}$. Legs $\overline{43} \overline{12}$, the third and fourth plainly longer than the first and second.

The spider is covered with a mixture of white, black, and bright rufus hairs, the different colors predominating on different parts so as to form the markings. Thus the cephalic plate is bright rufus and the middle line on the thoracic part pure white, while the abdomen shows a white band around the anterior end, and, on the posterior part of the dorsum, wide alternating transverse bands of rufus and black. These bands are not parallel but run upward and forward from the sides. The clypeus has long white hairs, and these are continued, rather sparsely, on to the falces. The legs are not conspicuous, being of a light brown color with darker rings and white hairs. The light brown palpus is covered with white hairs.

We have four females, sent by Dr. Braun, from Cape Colony.

\section{UNIDENTATI.}

JASODA, gen. nov.

The cephalothorax is high, with the sides nearly vertical and not far from parallel, although there is a slight swelling at the dorsal eyes, beyond which there is a very gradual contraction toward the posterior end. The cephalic part is a little inclined forward and the thoracic rounds off directly behind the dorsal eyes, falling more steeply after the first half. The quadrangle of the eyes occupies two-fifths of the cephalothorax, is nearly twice as wide as long, 
and is a very little wider behind than in front. The first row is curved downward, the eyes being small, and all separated, the lateral by nearly their diameter from the middle. The middle eyes are less than twice as large as the lateral. The second row is a little nearer the first than the third, and the third is nearly as wide as the cephalothorax. The falces are vertical, long, heavy, and parallel, with a short fang. There is one conical tooth on the inferior margin. The sternum is oblong, narrowing in front and behind and truncated in front. The first coxae are separated by about the width of the labium, which is longer than wide.

The eyes of this genus resemble those of Euryattus and Simaetha, but these genera belong respectively to the Pluridentati and the Fissidentati. Moreover the joints of the palpus are differently formed and proportioned, being flattened, with the tibia much longer than the tarsus, in Euryattus and Simaetha.

The type is a new species from Mashonaland.

\section{JASODA WOODII, sp. nov.}

$\delta$. Length $7 \mathrm{~mm}$. Legs $\overline{\mathrm{I}}_{34} 2$, not slender, nearly equal in thickness.

In our single specimen the cephalothorax and abdomen are both rubbed so that no idea of the marking can be formed. The cephalothorax is dark, almost black, with violet reflections. The abdomen is also dark but not glistening, and shows some long white hairs at the anterior end and on the sides. There are some long whitish hairs on the falces at the lower outer corner. The legs are light brown with slender black spines. The palpi are covered with white hairs.
We have one male sent to us by Mr. Guy A. K. Marshall, from Mashonaland, South Africa.

MeXCALA, gen. nov.

The cephalothorax is moderately high. It widens out more below than above, and is broader in the posterior part than in front. There is no marked difference in the planes of the cephalic and thoracic parts. The cephalic part is flat, and the thoracic falls from the dorsal eyes. The quadrangle of the eyes occupies a little more than one-third of the cephalothorax, is one-sixth wider than long, and is equally wide in front and behind. The anterior eyes are moderately large, the middle being less than twice as large as the lateral, and form a slightly curved row. The middle eyes are subtouching, with the lateral a little separated from them. The second row is halfway between the other two. The third row is a little narrower than the cephalothorax. The falces are vertical and stout, with a short fang, and have one conical tooth on the inferior margin. The sternum is oval, and truncated in front. The first coxae are separated by about the width of the labium, which is longer than wide. The pedicle is not visible. There are no constrictions. The abdomen is narrow in front and then widens.

Mexcala is distinguished from the other ant-like genera of this region by having a single conical tooth on the inferior margin of the falx. 
Mexcala RUFA, sp. nov.

8. Length $8 \mathrm{~nm}$. Legs 4132 , almost equal in stoutness, femora slightly thickened.

The cephalothorax is dark colored with a few black hairs on the eye-region, and some tiny white scale-like hairs on the front of the falces, and the lower edge of the clypeus, which pass around a little way, onto the sides of the cephalic part. The legs and palpi are black. The abdomen in our specimen, is rubbed, but seems to have been entirely covered with golden-yellow hairs which shade to white on the venter.

We have one male from Cape Colony, sent to us by Dr. Braun.

\section{QueKetTia, gen. nov.}

The cephalothorax is rather low, and is narrow in front, widening out behind the third row of eyes and then contracting behind. The upper surface is flat and almost entirely on the same plane, there being the gentlest possible rise from the two ends to the dorsal eyes. It is a little wider below than above. The quadrangle of the eyes is very slightly wider than long, is wider behind than in front, and occupies two-fifths of the cephalothorax. The anterior eyes are subtouching, in a straight row, the middle being twice as large as the lateral. The second row is much nearer the first than the third, and the third row is not quite so wide as the cephalothorax. The falces are very short, vertical and parallel with no tooth on the inferior margin. The sternum is oval, truncated in front. The first coxae are separated by a little more than the width of the labium, which is as wide as long. The pedicle is not visible from above. The relative length of the legs is $4 \times 23$, the first and second being short and much thickened, especially as to the femur and tibia. The type species is $6.5 \mathrm{~mm}$. long.

The short chubby front legs are enough to distinguish Quekettia from others of the group. The type is our Leptorchestes georgii from Madagascar, Ant-like Attidae, p. $5^{2}$.

This genus is named for Mr. J. F. Quekett, Curator of the Durban Museum, Natal, South Africa.

Kima gen. nov.

The cephalothorax is long, and has the sides nearly parallel. The cephalic part is on a higher plane than the thoracic which falls gently from the dorsal eyes. The upper surface is narrow, the sides widening out a very little below. The quadrangle of the eyes occupies twofifths of the cephalothorax, is nearly as long as wide, and is equally wide in front and behind. The anterior eyes are placed close together and form a row that is a little curved downward, the middle eyes being about twice as large as the lateral. The second row is much nearer the first than the third. The third row is nearly as wide as the cephalothorax. The falces are nearly horizontal, divergent and rather long, with a short fang, and have no tooth on the inferior margin. The sternum is narrow and oblong, and is truncated in front. The first coxae are separated by the width of the labium, which is plainly longer than wide. There is a distinct pedicle. In the type 
species there is a constriction in the middle of the abdomen.

This genus is distinguished from Quekettia by its more ant-like shape and by the abdominal constriction, as well as by the difference in the spines. Kima and Quekettia differ from Araegeus E. S. which also has no tooth on the inferior margin of the falx, by the shape of the sternum, which in Araegeus has a long point in front.

\section{KIMA AFRICANA, sp. nov.}

A large, ant-like species, with long slender legs and a long pedicle.

J. Length $8 \mathrm{~mm}$. Legs $4^{\mathrm{r}} 3^{2}$, fourth much the longest.

We have but one specimen. The cephalothorax is without hairs, the color being dark reddish brown, deepening to black on the cephalic plate. The fourth legs are black throughout their length, but the others, although black near the body, shade to brown at the extremities. They are equal in thickness and are but scantily haired. The first leg has three pairs of spines under the tibia, and two pairs under the metatarsus. The palpi are black. The rather high black clypeus has a few short white hairs. The abdomen, which has a construction in the middle, is covered with rich golden yellow hairs, which shade to white on the venter. The falces are reddish brown, and are flattened, with two teeth on the superior margin, at the distal end.

We have one male from Cape Colony, sent to us by Dr. Braun.

\section{Hyllus treleavenit sp. nov.}

․ Length $\mathrm{I} 3 \mathrm{~mm}$. Legs $\overline{3412}$.

In our specimen the cephalothorax is rubbed almost bare, showing the integument to be dark red on the sides and lighter above. There seem to have been many light yellow and reddish hairs on the sides and over the back. Around the eyes of the first row and on the clypeus are long reddish hairs, and white hairs with a yellow tinge cover the front faces of the falces. The abdomen has a covering of short reddish-gray hairs with long white hairs scattered over it. Down the middle is a herringbone stripe of white, and a white band around the base is continued on the sides to the middle point, where it ends in a conspicuous somewhat triangular white spot. Further back, on each side, is a crescent-shaped white spot. The legs are all hairy, especially the first pair, which has long black and white hairs below. Their general color is dark, but the metatarsi and tarsi of the first legs, as well as the distal ends of the metatarsi and the whole of the tarsi of the third and fourth, are lighter colored.

We have a single female from Mashonaland sent by Mr. Guy A. K. Marshall. We have named the species for Mr. F. Treleaven of Cape Town.

\section{Cyllobelus australis, sp. nov.}

Near Cyllobelus chionogaster E. S. but smaller, and lacking the red hairs around the eyes, and red marks on the cephalothorax and abdomen.

ㅇ. Length $5 \mathrm{~mm}$. Legs $4^{\mathrm{I}} 3^{2}$, fourth much the longest.

The cephalothorax is bronze-brown with a narrow white line running across the clypeus and entirely around the lower margin. The abdomen is bronze-brown with a large number of symmetrically disposed snow white spots. The two largest are somewhat triangular in shape and are placed on each side of the middle of the dorsum. There are smaller ones lower down on the sides, both before and behind these, and a single one just in front of the spinnerets. Six pairs of small white spots or lines extend from the 
base to just above the apex, over the middle of the dorsum. The underparts are of a dull silvery color. The falces are brown. The palpus is dark with a white spot on the patella and one on the tarsus. (In chionogaster the palpus is yellow with white spots). The legs are brown, the first pair having white marks on the patella and tarsus, and at the distal end of the tibia.

We have a single female sent to us by Dr. Braun from Algoa Bay, South Africa.

\section{RHENE BANKsII, sp. nov.}

8. Length 4.5. Legs 1423 , first plainly stoutest, with short fringe of hairs on under side of patella and tibia.

The cephalothorax is a little wider than long, and slants upward from the anterior eyes. The quadrangle is plainly wider behind than in front, is much wider than long, and occupies two-thirds of the cephalothorax, The anterior eyes form a straight row, and are close together, the middle being less than twice as large as the lateral. The second row is close to the first. The sternum is widest in the middle, pointed behind, and truncated in front. The anterior coxae are separated by barely the width of the labium, which is longer than wide. The falces are short, vertical and parallel.

The cephalothorax is dark with two white spots on the cephalic plate just in front of the dorsal eyes, and a curved white band on the front part. There is a white longitudinal line on the middle of the thoracic part, and a good many white hairs are seen on the sides. The abdomen is dark, with six white dots forming a curved line around the anterior end, and a transverse line of white dots in front of the middle of the dorsum. Near the posterior end is a large central white spot, from which a curved white line runs down on each side. There are some scattered white hairs on the clypeus. The first leg is dark with a short dark fringe under the patella and tibia, and a white spot at the distal end of the femur. The other legs have white rings at the ends of the joints, and are dark colored, excepting the tarsi and the proximal halves of the metatarsi, which are light.

We have a single male from Cape Town, sent by Dr. Braun.

Notes. - Mr. William H. Ashmead's memoir on the Hymenoptera Parasitica of the Hawaiian Islands occupies pages 277-364 of vol. I, part 3 of the Fauna Hawaiiensis and is illustrated by two uncolored plates. There are sections entitled : General considerations, Classification of the Hymenoptera, Systematic arrangement of the Hawaiian Hymenoptera, Distribution, Bibliographic, and Systematic account of the Hymenoptera Parasitica, the last forming the greater part of the text.

The description are concise, yet sufficiently detailed; a tabular separation of the species of each genus with more than a single representative is given in most instances.

One hundred and twenty-eight species are enumerated; those figured are new. Eleven genera only are considered peculiar to the Islands; most of the species are new so that a statement as to their distribution can not be made; of the known species, five are considered of Asiatic or Australian origin, seven of North American origin, and five of European origin.

The specification as to families, genera, and new species given on page $28 \mathrm{I}$ is not quite accurate, and that as to new species is not just to the author.

Mr. Ernest Hartet contributes to Novitates Zoologicae, vol. 8, no. 4, p. 494-506, an appreciative notice of the scientific work of the late William Doherty. A list of the papers based on Doherty's collections is given; also a list of seven articles on butterflies written by Doherty himself.

Correction:- Page 304, col. I, line 5 and line $\mathrm{I}_{4}$ for second read first. 

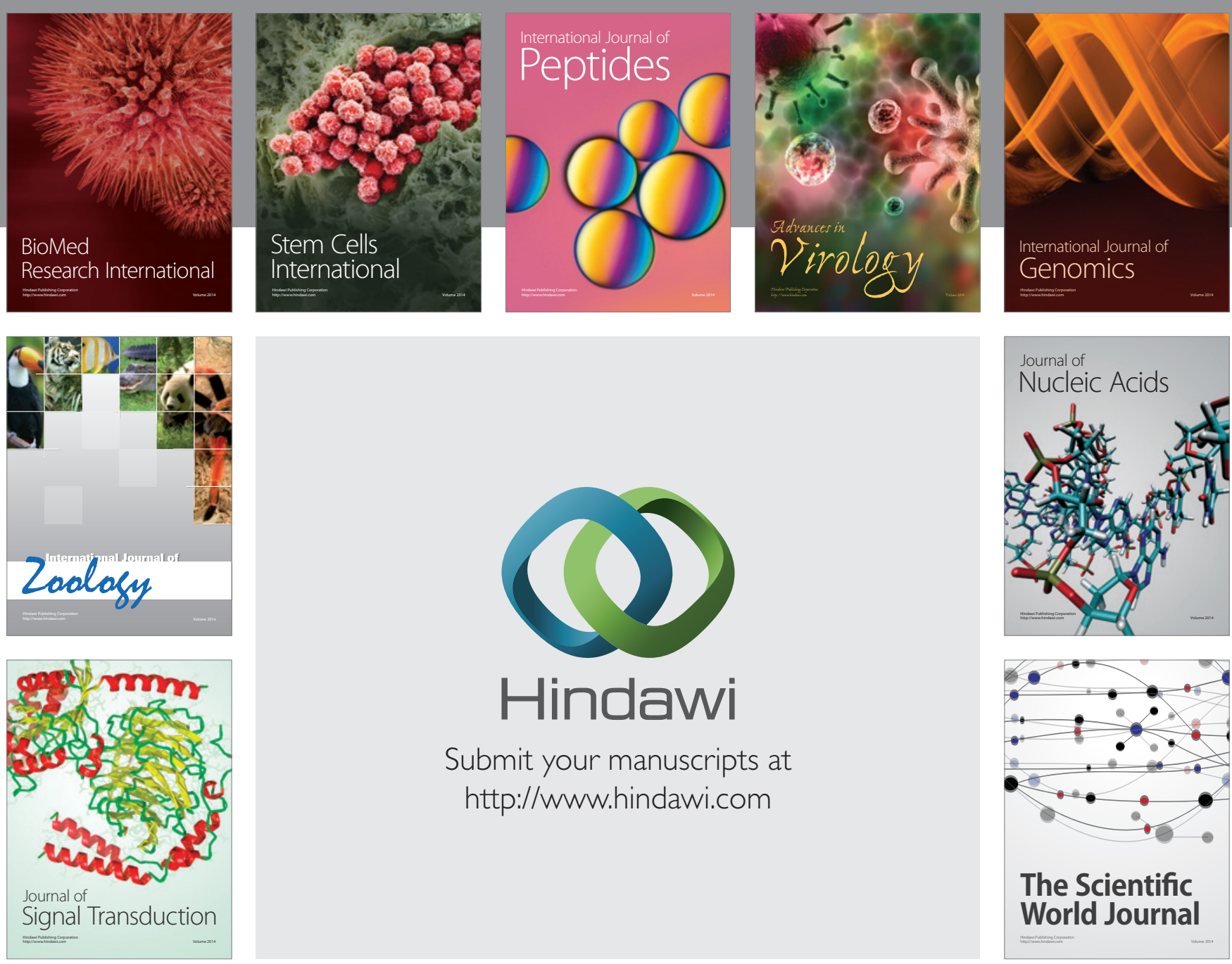

Submit your manuscripts at

http://www.hindawi.com
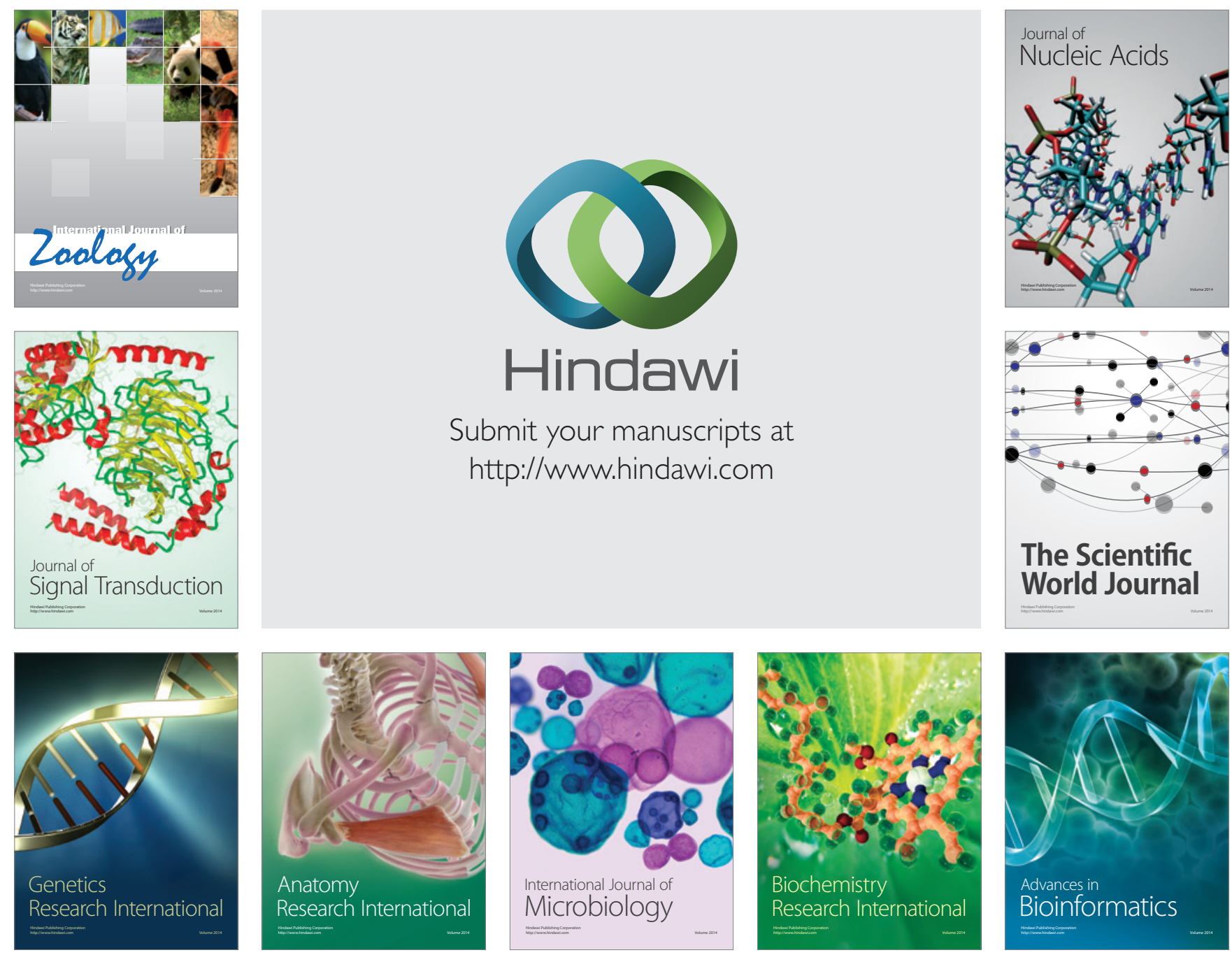

The Scientific World Journal
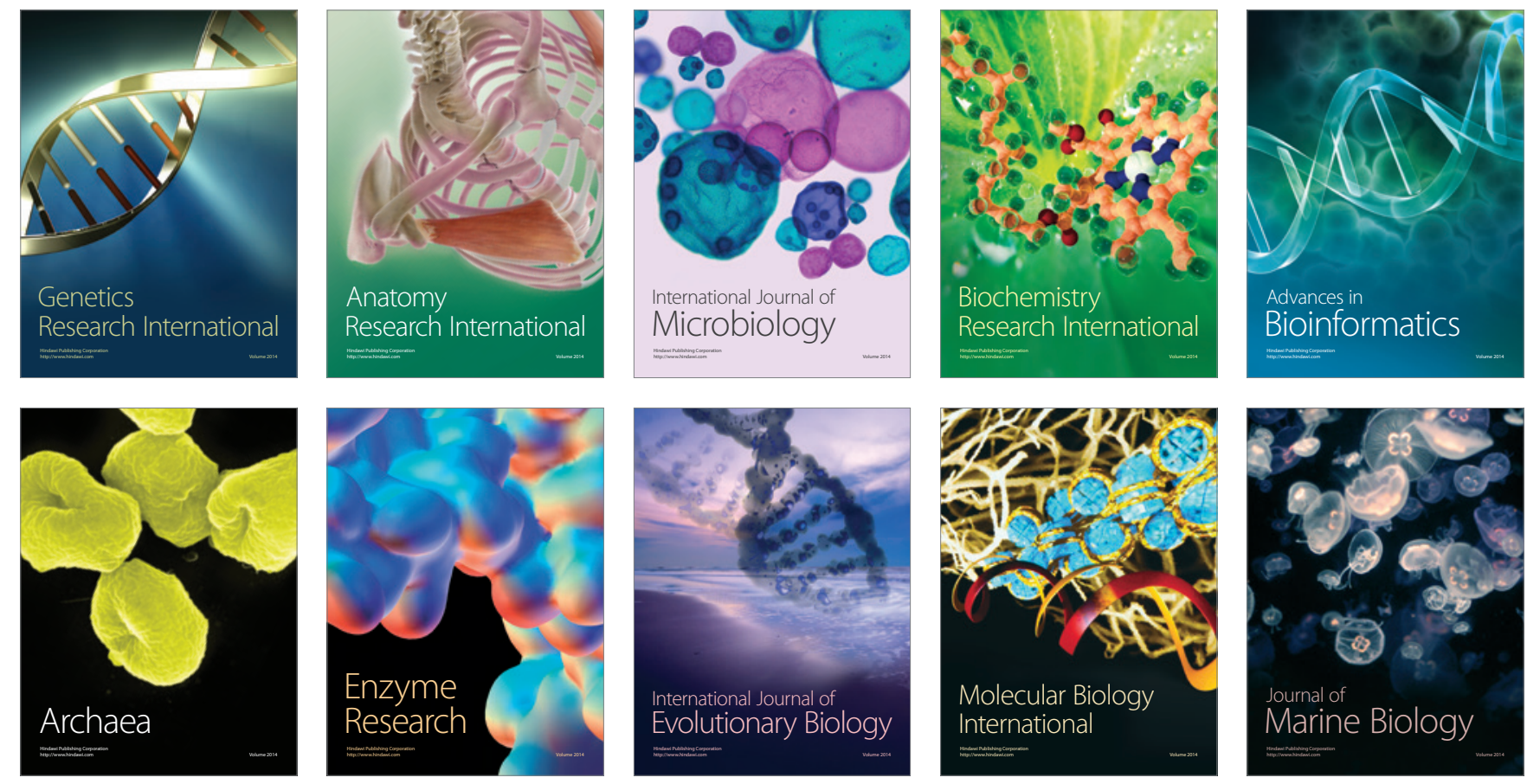